\section{Partial recording protocols for periodontal disease assessment in epidemiological surveys}

\author{
Protocolos de registros parciais para avaliação \\ da doença periodontal em levantamentos \\ epidemiológicos
}

\author{
1 Escola Nacional de Saúde \\ Pública Sergio Arouca, \\ Fundação Oswaldo Cruz, \\ Rio de Janeiro, Brasil. \\ 2 Associação Brasileira de \\ Odontologia/Seção Rio de \\ Janeiro, Petrópolis, Brasil. \\ 3 Faculdade de Odontologia \\ Universidade Federal do \\ Rio de Janeiro, \\ Rio de Janeiro, Brasil. \\ 4 Department of \\ Epidemiology and Public \\ Health, University College \\ London, London, U.K. \\ Correspondence \\ M. V. Vettore \\ Departamento de \\ Epidemiologia e Métodos \\ Quantitativos em Saúde, \\ Escola Nacional de Saúde \\ Pública Sergio Arouca, \\ Fundação Oswaldo Cruz. \\ Av. Leopoldo Bulhões 1480, \\ Rio de Janeiro, $R J$ \\ 21041-210, Brasil. \\ mario@ensp.fiocruz.br
}

\begin{abstract}
The objective of the present study was to compare the reliability of four partial-mouth protocols for assessing shallow, moderate, and deep sites for periodontal pocket depth and clinical attachment levels. Periodontal pocket depth and clinical attachment level measurements were recorded for 156 subjects (age $\geq 30$ ). The four models of partial-mouth protocols compared were: Model I: all sites per tooth in the random half-mouth protocol randomly selecting one maxillary and mandibular quadrant, Model II: buccal sites in a full-mouth protocol, Model III: buccal sites in the random half-mouth protocol randomly selecting one maxillary and mandibular quadrant, Model IV: all sites per tooth using Community Periodontal Index teeth. In comparison with full mouth examination, Model I did not show significant differences for periodontal pocket depth and clinical attachment level parameters. Models II and III were different for some periodontal pocket depth means, and Model IV significantly overestimated all clinical parameters related to periodontal disease. Model I appears to be adequate to substitute for the full-mouth examination to assess the prevalence and severity of chronic periodontal disease in adults.
\end{abstract}

Periodontal Disease; Oral Health; Health Survey; Protocols

\author{
Mario Vianna Vettore 1 \\ Gabriela de Almeida Lamarca 2 \\ Anna Thereza Thomé Leão 3 \\ Aubrey Sheiham 4 \\ Maria do Carmo Leal 1
}

\section{Introduction}

Oral health surveys are conducted to assess the oral health situation and monitor programs in oral health. The two major dental diseases are periodontal disease and dental caries. Chronic periodontitis is the most common form of destructive periodontal disease in adults. It is characterized by loss of clinical attachment due to destruction of the periodontal ligament and loss of the adjacent alveolar bone ${ }^{1}$. The clinical parameters employed to characterize the severity and prevalence of chronic periodontitis include bleeding on probing, radiographic methods, periodontal pocket depth, and clinical attachment level measurements. The latter two are the most reliable parameters employed to characterize periodontal tissue breakdown throughout life 2

Most survey methods use a full-mouth assessment of periodontal diseases. This involves the examination of 6 sites on all teeth, involving up to 168 sites per mouth (excluding 3rd molars). This results in 168 measurements for each periodontal pocket depth and clinical attachment level parameter, involving at least 336 pieces of clinical data for each subject 3 . Because of the time, logistic, and cost constraints for a fullmouth assessment in epidemiological surveys involving large population samples, the full-mouth clinical assessment of periodontal diseases is impractical 3 . Therefore partial recording protocols 
have been developed and used to characterize the periodontal status of subjects and populations ${ }^{3}$. Such protocols for periodontal assessment can employ periodontal indices such as Russell's Index ${ }^{4}$, the Simplified Oral Hygiene Index 5 , Periodontal Disease Index ${ }^{6}$, the Extent and Severity Index 7 and the Community Periodontal Index of Treatment Needs (CPITN) 8, changed to the Community Periodontal Index (CPI) 9.

Periodontal indices combine clinical characteristics and periodontal parameters to provide an individual score of periodontal status. The CPITN was originally developed by the World Health Organization to screen for periodontal treatment needs in large populations, characterize the type of periodontal care, and detect the profile of trainees required to establish the periodontal health in populations ${ }^{8}$. CPITN 8 was modified to CPI 9 . Nowadays CPI has been recommended to characterize the prevalence of periodontal disease in epidemiological studies because it is a simple and rapid method and provides international standardization 10,11. The limitations of CPI are its inability to provide an adequate assessment of prevalence of periodontal disease. This has stimulated periodontal epidemiologists to develop new methods to reliably assess periodontal disease. To do so, partialmouth protocols have been proposed as a robust methodology for periodontal status assessment. Partial-mouth protocols involve examination of a subgroup of tooth sites and/or teeth using conventional parameters 12. Different models of partial-mouth protocols such as reduction in quadrants, teeth, sites, or combinations of the above have been suggested and compared with full-mouth examinations 3,13,14,15,16,17,18,19,20.

Reliable partial-mouth protocols to characterize the periodontal status would help reduce the cost and time for epidemiological surveys while maintaining validity of data with unbiased results. However, there is no consensus about what model of partial-mouth protocol should replace the system used in CPI to assess periodontal diseases in epidemiological surveys.

The objective of the present study was to compare the reliability of four models of partialmouth protocols for assessing shallow, moderate, and deep periodontal sites for periodontal pocket depth and clinical attachment levels in subjects with different levels of periodontal disease.

\section{Materials and methods}

The present investigation consisted of a crosssectional analysis of periodontal clinical measurements provided by two databases to test four models of partial-mouth protocols. One database consisted of subjects selected in the Dental Clinic Department at the Universidade Federal do Rio de Janeiro (UFRJ study). These subjects had participated in a study to test the association between periodontal disease and psychosocial factors 21 . The other source was pregnant women who were participants in a study to assess the relationship between periodontal disease and preterm low birth weight at the Escola Nacional de Saúde Pública Sergio Arouca, Fundação Oswaldo Cruz (ENSP/FIOCRUZ study). The latter subjects were selected in public maternity clinics in the city of Rio de Janeiro, Brazil.

The two studies were approved by the respective Research Ethics Committees at UFRJ and ENSP/FIOCRUZ. All subjects gave written consent after receiving information concerning the research objectives.

Pilot studies were conducted to calibrate two examiners for the UFRJ study and six examiners for the ENSP/FIOCRUZ study of periodontal clinical parameters. All examiners in both studies were trained and calibrated by the first author (M.V.V.). The data for full-mouth examination (6 sites per tooth/ all teeth, except third molars) for periodontal pocket depth and clinical attachment loss were measured at 6 sites per tooth (mesio-buccal, buccal, disto-buccal, disto-lingual, lingual and mesio-lingual) on all teeth excluding third molars. Periodontal pocket depth and clinical attachment level measures were recorded to the nearest millimeter using the North Carolina periodontal probe (Hu-friedy, Chicago, USA).

The inclusion criteria were that all subjects should be over 30 years of age and have at least 15 teeth. Patients were excluded if they presented with acute necrotizing ulcerative gingivitis/periodontitis, systemic conditions associated with periodontal disease, were taking either medication related to periodontal changes or psychotropic drugs, or if they had received periodontal treatment during the previous six months or antibiotics during the last week. In addition, subjects were excluded who had suffered from rheumatic fever or endocarditis and would require prophylactic antibiotics for periodontal examination.

The comparison of periodontal pocket depth and clinical attachment loss against full-mouth examination was conducted for four different models of partial-mouth protocols. Model I employed the random half-mouth protocol randomly selecting one maxillary and mandibular quadrant and evaluated disease at all sites per tooth. Model II employed buccal sites (mesiobuccal, buccal, disto-buccal) in a full-mouth protocol. In Model III the random half-mouth 
protocol randomly selecting one maxillary and mandibular quadrant and evaluated disease in all buccal sites. Model IV consisted of the assessment at all sites per tooth for the CPI teeth ${ }^{9}$. The CPI teeth use a fixed subset of teeth, including teeth numbers $16,17,11,26,27,36,37,31,46$, and 47 according to the Federation Dentaire Internationale numbering system.

A random draw was conducted to select the two quadrants in Models II and III using a coin flip. In the first flip of the coin, quadrant I or II was picked, and in a second flip quadrant III or IV was picked.

The selected subjects were assigned to one of three groups in accordance with their levels of probing pocket depth. Group A subjects had fewer than 4 sites with probing pocket depth = $4.0 \mathrm{~mm}$. Groups B and C consisted of subjects with at least 4 sites with probing pocket depth $\geq 4.0 \mathrm{~mm}$ and $\leq 6.0 \mathrm{~mm}$, and at least 4 sites with probing pocket depth $>6.0 \mathrm{~mm}$, respectively.

Socioeconomic data, including mean age, gender, employment status, marital status, schooling, and family income were computed for each participant. The three groups were compared with respect to age using a Kruskal-Wallis test, and for the remaining socioeconomic data $\chi^{2}$ tests were performed.

The full-mouth examination for periodontal clinical parameters was registered for each subject, and then the means and frequencies were calculated for periodontal pocket depth and clinical attachment loss, for full-mouth examination and partial-mouth protocol models individually and across the full-mouth examination and partial-mouth protocol models and groups.

Differences between clinical parameters were examined in site subsets according to periodontal pocket depth and clinical attachment level of $<4,4-6$, and $>6 \mathrm{~mm}$. Values for each clinical parameter were averaged separately for the 3 above-mentioned periodontal pocket depths and clinical attachment level categories for each subject and then averaged across subjects in the full-mouth examination and partial-mouth protocol models.

In order to test the characterization of prevalence and severity of periodontal disease, significance of differences between full-mouth examination and partial-mouth protocol Models I, II, III, and IV were checked separately by the Wilcoxon test. The Kruskal-Wallis test was used to test the differences between Groups A, B, and $\mathrm{C}$ for full-mouth examination and partial-mouth protocol Models. All statistical analyses were performed using a commercial statistical program, SPSS (SPSS Inc., Chicago, USA). The significance level for all analyses was set at $5 \%(p \leq 0.05)$.

\section{Results}

\section{Demographic and socioeconomic data}

The sample population consisted of 156 subjects; 79 in the UFRJ study and 77 in the ENSP/FIOCRUZ study. Age ranged from 30 to 67 years (mean $40.29 \pm 6.09$ ); $76 \%$ were female. Mean age of patients in the UFRJ and ENSP/FIOCRUZ studies was $46.89 \pm 7.83$ and $34.36 \pm 3.20$, respectively. All participants in the ENSP/FIOCRUZ study were females, while $30.7 \%$ of the UFRJ study subjects were males. In the UFRJ and ENSP/FIOCRUZ studies, $77.3 \%$ and $50.4 \%$ were employed, $46.6 \%$ and $73.4 \%$ were married, and $62.1 \%$ and $53.2 \%$ had more than 8 years of schooling, respectively. The demographic and socioeconomic characteristics were similar in Groups A, B, and C, with the exception of age and gender (Table 1).

\section{Clinical calibration}

The Kappa index and intraclass correlation coefficient for agreement of findings for periodontal pocket depth ranged from 0.73 to 0.92 and 0.72 to 0.99 for intra-examiner calibration. Inter-examiner Kappa index and intraclass correlation coefficient of agreement in findings varied from 0.76 to 0.86 and 0.72 to 0.88 for periodontal pocket depth (Table 2).

\section{Clinical parameters}

The individual mean number of teeth for Groups $\mathrm{A}, \mathrm{B}$, and C were $21.13,22.27$, and 21.94, respectively. The mean clinical measures $( \pm \mathrm{SD})$ for periodontal pocket depth and clinical attachment loss for the three groups were: A, $1.72 \pm 0.54$ and $2.04 \pm 0.64 \mathrm{~mm} ; \mathrm{B}, 2.67 \pm 0.67$, and $3.10 \pm 0.76 \mathrm{~mm}$; $\mathrm{C}, 4.14 \pm 1.23$ and $5.01 \pm 1.60 \mathrm{~mm}$ for the UFRJ study and A, $1.68 \pm 0.74$ and $1.75 \pm 0.79 \mathrm{~mm}$; $\mathrm{B}$, $2.41 \pm 1.17$ and $2.47 \pm 1.25 \mathrm{~mm} ; \mathrm{C}, 3.93 \pm 1.38$ and $3.93 \pm 1.38$ for the ENSP/FIOCRUZ study.

Subjects were grouped into three groups according to presence and severity of periodontal disease: Group A = 44 subjects (UFRJ = 22), Group $\mathrm{B}=81(\mathrm{UFRJ}=27)$ subjects, and Group $\mathrm{C}=31$ $(\mathrm{UFRJ}=30)$ subjects.

Mean scores for clinical measures for periodontal pocket depth and clinical attachment loss for full-mouth examination and partial-mouth protocol Models were full-mouth examination $(2.60 \pm 1.10,2.90 \pm 1.40)$, Model I $(2.60 \pm 1.12,2.90$ $\pm 1.38)$, Model II ( $2.56 \pm 1.08,2.87 \pm 1.36)$, Model III $(2.57 \pm 1.11,2.87 \pm 1.35)$, and Model IV (2.93 \pm 1.28, $3.33 \pm 1.66$ ) (Table 3). Periodontal clinical scores were similar in full-mouth examination and Model I while statistically significant differ- 
Demographic and socioeconomic characteristics of subjects distributed in Groups A, B, and C.

\begin{tabular}{|c|c|c|c|c|}
\hline $\begin{array}{l}\text { Demographic and } \\
\text { socioeconomic characteristics }\end{array}$ & Group A $(n=44)$ & Group $B(n=81)$ & Group C ( $n=31)$ & $p$ \\
\hline Age $($ mean $\pm S D)$ * & $40.33 \pm 8.63$ & $38.11 \pm 7.87$ & $45.43 \pm 6.38$ & $<0.001$ \\
\hline Gender (\%) ** & & & & $<0.001$ \\
\hline Male & 28.2 & 8.4 & 42.9 & \\
\hline Female & 71.8 & 91.6 & 57.1 & \\
\hline Employment status (\%) *夫 & & & & 0.485 \\
\hline Unemployed & 7.7 & 12.0 & 14.3 & \\
\hline Employed & 87.1 & 84.4 & 76.2 & \\
\hline Retired & 5.1 & 3.6 & 9.5 & \\
\hline Marital status (\%) ** & & & & 0.275 \\
\hline Single/Alone & 26.4 & 22.9 & 17.3 & \\
\hline Married/Partner & 70.2 & 62.4 & 60.3 & \\
\hline Divorced/Separated & 3.4 & 12.3 & 17.7 & \\
\hline Widow & 10.0 & 2.4 & 4.7 & \\
\hline \multicolumn{5}{|l|}{ Subject's schooling (\%) ** } \\
\hline$<8$ years & 36.8 & 46.2 & 23.8 & 0.159 \\
\hline$\geq 8$ years & 63.2 & 53.8 & 76.2 & \\
\hline
\end{tabular}

* Kruskal-Wallis Test:

** Qui-square Test.

Table 2

Results of intra and inter-examiner calibration for periodontal pocket depth.

\begin{tabular}{|c|c|c|c|c|c|c|c|c|c|c|c|c|c|}
\hline \multirow[b]{2}{*}{ Study } & \multirow[b]{2}{*}{ Trainee } & \multicolumn{2}{|c|}{$\begin{array}{c}\text { Intra-examiner } \\
\text { calibration }\end{array}$} & \multirow[b]{2}{*}{ K-test } & \multirow[b]{2}{*}{ ICC } & \multirow[b]{2}{*}{ K-test } & \multicolumn{4}{|c|}{ Inter-examiner calibration } & \multirow[b]{2}{*}{ ICC } & \multirow[b]{2}{*}{ K-test } & \multirow[b]{2}{*}{ ICC } \\
\hline & & K-test & ICC & & & & ICC & K-test & ICC & K-test & & & \\
\hline \multirow[t]{2}{*}{ UFRJ study } & 1 & 0.73 & 0.99 & 0.86 & 0.88 & & & & & & & & \\
\hline & 2 & 0.83 & 0.97 & & & & & & & & & & \\
\hline \multirow[t]{6}{*}{ ENSP/FIOCRUZ study } & 1 & 0.78 & 0.72 & 2: 0.77 & 2: 0.72 & 3: 0.81 & 3: 0.78 & 4: 0.83 & 4: 0.77 & 5: 0.85 & 5: 0.80 & 6: 0.79 & 6: 0.75 \\
\hline & 2 & 0.92 & 0.86 & 3: 0.78 & $3: 0.73$ & 4: 0.80 & 4: 0.76 & 5: 0.81 & $5: 0.76$ & 6: 0.77 & 6: 0.72 & & \\
\hline & 3 & 0.83 & 0.80 & 4: 0.84 & 4: 0.80 & 5: 0.82 & 5: 0.78 & $6: 0.79$ & 6: 0.75 & & & & \\
\hline & 4 & 0.79 & 0.76 & 5: 0.78 & 5: 0.72 & 6: 0.76 & 6: 0.72 & & & & & & \\
\hline & 5 & 0.85 & 0.79 & $6: 0.80$ & 6: 0.77 & & & & & & & & \\
\hline & 6 & 0.81 & 0.77 & & & & & & & & & & \\
\hline
\end{tabular}

K-test = Kappa test; ICC = Intraclass Coefficient Correlation; UFRJ study = Universidade Federal do Rio de Janeiro study;

ENSP/FIOCRUZ study = Escola Nacional de Saúde Pública Sergio Arouca, Fundação Oswaldo Cruz study.

ences for periodontal pocket depth means were observed between full-mouth examination and Model II and between full-mouth examination and Model III (Wilcoxon test, $\mathrm{p}<0.05$ ). Compared with full-mouth examination, Model II and Model III underestimated the mean periodontal pocket depth by $1.54 \%$ and $1.15 \%$, respectively. Frequencies and means of shallow and moderate periodontal pocket depth sites between full-mouth examination and Model II were significantly different (Table 3). No significant differences were found for other periodontal parameters between Model II and full-mouth examination, and between Model III and full-mouth examination. Statistically significant differences were found between full-mouth examination and Model IV for all periodontal clinical parameters. In this analysis, Model IV overestimated the mean peri- 
Comparison of mean and mean frequencies for shallow, moderate, and deep sites between full-mouth examination and partial-mouth protocol models.

\begin{tabular}{|c|c|c|c|c|c|}
\hline Full-mouth examination & \multicolumn{2}{|c|}{ Model I } & Model II & \multirow[t]{2}{*}{ Model III } & \multirow[t]{2}{*}{ Model IV } \\
\hline \multicolumn{4}{|l|}{ Periodontal pocket depth } & & \\
\hline$X \pm S D$ & $2.60 \pm 1.10$ & $2.60 \pm 1.12$ & $2.56 \pm 1.08$ * & $2.57 \pm 1.11^{\star}$ & $2.93 \pm 1.28$ * \\
\hline \multicolumn{6}{|l|}{$X \%$ sites } \\
\hline$<4 \mathrm{~mm}$ & $79.87 \pm 22.34$ & $79.94 \pm 22.97$ & $80.89 \pm 21.01^{*}$ & $80.46 \pm 22.21$ & $73.26 \pm 24.67^{*}$ \\
\hline $4-6 m m$ & $16.97 \pm 17.34$ & $16.88 \pm 17.90$ & $15.95 \pm 15.93^{*}$ & $16.39 \pm 17.16$ & $22.43 \pm 18.56^{*}$ \\
\hline$>6 \mathrm{~mm}$ & $3.15 \pm 8.54$ & $3.18 \pm 8.97$ & $3.16 \pm 8.80$ & $3.15 \pm 9.21$ & $5.21 \pm 12.35^{\star}$ \\
\hline \multicolumn{6}{|l|}{ Clinical attachment loss } \\
\hline$X \pm S D$ & $2.90 \pm 1.40$ & $2.90 \pm 1.38$ & $2.87 \pm 1.36$ & $2.87 \pm 1.35$ & $3.33 \pm 1.66^{\star}$ \\
\hline \multicolumn{6}{|l|}{$X \%$ sites } \\
\hline$<4 \mathrm{~mm}$ & $74.53 \pm 26.53$ & $74.51 \pm 26.92$ & $75.09 \pm 25.64$ & $74.70 \pm 26.27$ & $66.46 \pm 29.24^{\star}$ \\
\hline $4-6 m m$ & $19.93 \pm 18.67$ & $20.05 \pm 19.45$ & $19.48 \pm 17.61$ & $19.91 \pm 18.91$ & $24.70 \pm 19.57^{\star}$ \\
\hline$>6 \mathrm{~mm}$ & $5.54 \pm 13.36$ & $5.44 \pm 13.33$ & $5.43 \pm 13.10$ & $5.39 \pm 13.11$ & $8.84 \pm 18.06^{*}$ \\
\hline
\end{tabular}

* $p<0.05$, refers to Wilcoxon test between full-mouth examination and Models I, II, III, and IV, separately;

** Qui-square test.

Model I: All sites per tooth in a random half-mouth protocol (one maxillary and one mandibular);

Model II: Buccal sites in a full-mouth protocol;

Model III: Buccal sites in a random half-mouth protocol (one maxillary and one mandibular);

Model IV: All sites per tooth at Community Periodontal Index teeth.

odontal pocket depth and clinical attachment loss by $12.7 \%$ and $14.83 \%$.

In comparison with full-mouth examination, the frequency of periodontal pocket depth shallow sites was underestimated in $8.3 \%$ of sites when CPI teeth (Model IV) were employed and overestimated by $32.2 \%$ and $64.9 \%$ in the moderate and deep periodontal pocket depth sites. In clinical attachment loss, shallow site prevalence was underestimated in $12.5 \%$ sites and the frequency of moderate and deep sites was overestimated in $25.4 \%$ and $102.3 \%$ sites, respectively.

Tables 4 and 5 show the distribution of all subjects among the three groups based on prevalence and severity of periodontal disease for full-mouth examination and partial-mouth protocol models. A comparison of periodontal pocket depth and clinical attachment loss measurements among Groups A, B, and C was conducted for full-mouth examination and partialmouth protocol models. There were significant differences for means and frequencies of shallow, moderate, and deep sites for periodontal pocket depth and clinical attachment loss between the full-mouth examination group and the partialmouth protocol models.

There were no differences between partialmouth protocol models and full-mouth examination for periodontal pocket depth when comparisons were done for Groups A and B, except for Model IV. In Group C, only Model I was similar to full-mouth examination for periodontal pocket depth (Table 4). Clinical attachment loss measurements did not differ between full-mouth examination and Models I and III for all groups. In Group B analysis for clinical attachment loss parameters, all the partial-mouth protocol Models were not different from full-mouth examination, except Model IV (Table 5).

\section{Discussion}

The objective of estimating levels of periodontal disease in populations is to determine the prevalence, distribution, and progression of the disease and treatment needs, besides evaluating preventive and therapeutic procedures 22 . Periodontal disease can be assessed by full-mouth examination, periodontal indexes, or partialmouth protocols ${ }^{3}$. While the indexes combine different parameters in an individual score, the partial-mouth protocols register the same parameters as the conventional periodontal clinical examination, but in a smaller number of teeth and/or sites. Comparison of periodontal disease prevalence and severity between individuals or populations using different registration systems cannot be adequate if the methods' precision varies. 
Comparison of mean and mean frequencies of shallow, moderate, and deep sites for periodontal pocket depth among Groups A, B, and C for full-mouth examination and partial-mouth protocol models, and between full-mouth examination and each partial-mouth protocol model according to group (A, B, and C).

\begin{tabular}{|c|c|c|c|c|c|c|}
\hline Group & $\begin{array}{c}\text { Clinical } \\
\text { parameters }\end{array}$ & $\begin{array}{l}\text { Full-mouth } \\
\text { examination }\end{array}$ & Model I & Model II & Model III & Model IV \\
\hline & $X \pm S D$ & $1.69 \pm 0.46$ & $1.71 \pm 0.46$ & $1.69 \pm 0.47$ & $1.71 \pm 0.48$ & $1.87 \pm 0.50$ * \\
\hline & $X \%$ of sites & & & & & \\
\hline Group A & $<4 \mathrm{~mm}$ & $98.15 \pm 3.31$ & $98.10 \pm 3.12$ & $98.02 \pm 3.45$ & $97.63 \pm 3.98$ & $96.29 \pm 6.05$ * \\
\hline \multirow[t]{4}{*}{$(n=44)$} & $4-6 \mathrm{~mm}$ & $1.83 \pm 3.30$ & $1.86 \pm 3.07$ & $1.95 \pm 3.44$ & $2.29 \pm 3.93$ & $3.90 \pm 6.13$ * \\
\hline & $>6 \mathrm{~mm}$ & $0.02 \pm 0.14$ & $0.04 \pm 0.25$ & $0.04 \pm 0.28$ & $0.08 \pm 0.50$ & $0.08 \pm 0.50$ \\
\hline & $X \pm S D$ & $2.49 \pm 0.54$ & $2.51 \pm 0.58$ & $2.47 \pm 0.54$ & $2.48 \pm 0.61$ & $2.81 \pm 0.66$ * \\
\hline & $X \%$ of sites & & & & & \\
\hline Group B & $<4 \mathrm{~mm}$ & $82.82 \pm 11.62$ & $83.07 \pm 12.56$ & $83.29 \pm 11.90$ & $82.78 \pm 13.99$ & $74.32 \pm 15.69$ * \\
\hline \multirow[t]{4}{*}{$(n=81)$} & $4-6 m m$ & $16.48 \pm 11.05$ & $16.08 \pm 11.72$ & $15.93 \pm 11.37$ & $16.26 \pm 13.08$ & $24.23 \pm 14.35$ * \\
\hline & $>6 \mathrm{~mm}$ & $0.70 \pm 1.64$ & $0.86 \pm 2.58$ & $0.79 \pm 1.84$ & $0.95 \pm 2.77$ & $1.45 \pm 4.51$ * \\
\hline & $X \pm S D$ & $4.41 \pm 1.21$ & $4.13 \pm 1.29$ & $4.02 \pm 1.25$ * & $4.02 \pm 1.34$ & $4.77 \pm 1.31$ * \\
\hline & $X \%$ of sites & & & & & \\
\hline Group C & $<4 \mathrm{~mm}$ & $46.20 \pm 22.78$ & $46.00 \pm 24.29$ & $50.32 \pm 21.82$ * & $50.02 \pm 24.48$ * & $36.63 \pm 17.37$ * \\
\hline \multirow[t]{3}{*}{$(n=31)$} & $4-6 \mathrm{~mm}$ & $39.83 \pm 18.33$ & $40.30 \pm 19.43$ & $35.92 \pm 15.78$ * & $36.70 \pm 18.03$ & $42.25 \pm 16.17$ \\
\hline & $>6 \mathrm{~mm}$ & $13.97 \pm 14.76$ & $13.70 \pm 15.96$ & $13.75 \pm 15.67$ & $13.27 \pm 16.87$ & $22.31 \pm 18.82$ * \\
\hline & $p^{\star \star}$ & $<0.0001$ & $<0.0001$ & $<0.0001$ & $<0.0001$ & $<0.0001$ \\
\hline
\end{tabular}

${ }^{*} p<0.05$, refers to Wilcoxon test between full-mouth examination and each partial-mouth protocol model;

** $\mathrm{p}$ refers to Kruskall-Wallis test.

Model I = All sites per tooth in a random half-mouth protocol (one maxillary and one mandibular);

Model II = Buccal sites in a full-mouth protocol;

Model III = Buccal sites in a random half-mouth protocol (one maxillary and one mandibular);

Model IV = All sites per tooth at Community Periodontal Index teeth:

Group $A=$ subjects with fewer than 4 sites with periodontal pocket depth $=4.0 \mathrm{~mm}$;

Group $B=$ subjects with at least 4 sites with periodontal pocket depth $\geq 4.0 \mathrm{~mm}$ and $\leq 6.0 \mathrm{~mm}$;

Group $C=$ subjects with at least 4 sites with periodontal pocket depth $>6.0 \mathrm{~mm}$.

The effectiveness of partial-mouth protocols to characterize periodontal disease in adult populations has been properly described $3,13,14,15,16,17,18,19$, but not for early-onset periodontitis 17,23 . In the present study, subjects over 29 years of age were examined for periodontal pocket depth and clinical attachment loss in order to test the level of reliability of different partial-mouth protocols compared to full-mouth examination. The partial-mouth protocol models tested were heterogeneous for characterizing the prevalence and severity of periodontal disease. There were no significant differences between Model I and full-mouth examination for all clinical parameters, although half of the periodontal sites were examined. Model I appeared to be adequate for replacing full-mouth examination to characterize the prevalence and severity of chronic periodontal disease in adult populations. This finding occurred when subjects were analyzed as one overall group as well as when they were analyzed according to Groups A, B, and C. The unbiased estimates obtained by Model I for both periodontal pocket depth and clinical attachment loss have been described previously $13,15,18,24$. Half-mouth assessment resulted in an almost identical population mean clinical attachment loss 13,15,18 and mean periodontal pocket depth 18 and prevalence of clinical attachment loss 24 as compared to that computed from fullmouth data. This finding is very useful for epidemiological studies involving periodontal status assessment, since there would be considerable reduction in time for examination, while preserving reliability.

Since Model I employed the random halfmouth protocol, randomly selecting one maxillary and mandibular quadrant, and evaluated disease at all sites per tooth, it seems reasonable to assume that one right or left maxillary and 
Comparison of mean and mean frequencies of shallow, moderate, and deep sites for clinical attachment level among Groups A, B, and C for full-mouth examination and partial-mouth protocol models, and between full-mouth examination and each partial-mouth protocol model according to group (A, B, and C).

\begin{tabular}{|c|c|c|c|c|c|c|}
\hline Group & $\begin{array}{c}\text { Clinical } \\
\text { parameters }\end{array}$ & $\begin{array}{l}\text { Full-mouth } \\
\text { examination }\end{array}$ & Model I & Model II & Model III & Model IV \\
\hline & $X \pm S D$ & $1.87 \pm 0.53$ & $1.88 \pm 0.54$ & $1.90 \pm 0.55$ * & $1.89 \pm 0.58$ & $2.13 \pm 0.68$ * \\
\hline & $X \%$ of sites & & & & & \\
\hline Group A & $<4 \mathrm{~mm}$ & $95.44 \pm 6.80$ & $95.33 \pm 7.19$ & $94.76 \pm 7.35$ * & $94.55 \pm 8.42$ & $91.81 \pm 11.77$ * \\
\hline \multirow[t]{3}{*}{$(n=44)$} & $4-6 \mathrm{~mm}$ & $4.39 \pm 6.26$ & $4.55 \pm 6.91$ & $5.02 \pm 6.64$ * & $5.29 \pm 8.32$ & $7.63 \pm 10.59$ * \\
\hline & $>6 \mathrm{~mm}$ & $0.17 \pm 0.75$ & $0.12 \pm 0.44$ & $0.22 \pm 0.99$ & $0.16 \pm 0.73$ & $0.56 \pm 2.05$ * \\
\hline & $X \pm S D$ & $2.67 \pm 0.65$ & $2.68 \pm 0.68$ & $2.64 \pm 0.62$ & $2.66 \pm 0.68$ & $3.04 \pm 0.89$ * \\
\hline Group B & $X \%$ of sites & & & & & \\
\hline \multirow[t]{5}{*}{$(n=81)$} & $<4 \mathrm{~mm}$ & $79.00 \pm 14.94$ & $79.06 \pm 15.99$ & $79.59 \pm 14.13$ & $78.88 \pm 15.84$ & $69.40 \pm 19.45$ \\
\hline & $4-6 \mathrm{~mm}$ & $19.42 \pm 13.67$ & $19.28 \pm 14.53$ & $18.91 \pm 12.93$ & $19.39 \pm 14.34$ & $27.59 \pm 16.94$ * \\
\hline & $>6 \mathrm{~mm}$ & $1.58 \pm 3.28$ & $1.66 \pm 3.63$ & $1.50 \pm 3.14$ & $1.73 \pm 3.76$ & $3.01 \pm 7.73$ * \\
\hline & $\mathrm{X} \pm \mathrm{SD}$ & $4.98 \pm 1.60$ & $4.92 \pm 1.50$ & $4.88 \pm 1.59$ * & $4.82 \pm 1.51$ & $5.80 \pm 1.69$ * \\
\hline & $X \%$ of sites & & & & & \\
\hline Group C & $<4 \mathrm{~mm}$ & $33.17 \pm 22.62$ & $33.05 \pm 22.84$ & $35.38 \pm 23.13$ * & $35.58 \pm 24.25$ & $22.81 \pm 16.62$ * \\
\hline \multirow[t]{3}{*}{$(n=31)$} & $4-6 m m$ & $43.32 \pm 18.08$ & $44.08 \pm 19.28$ & $41.51 \pm 16.83$ & $42.02 \pm 19.54$ & $41.35 \pm 17.82$ \\
\hline & $>6 \mathrm{~mm}$ & $23.51 \pm 21.78$ & $22.87 \pm 22.10$ & $23.11 \pm 21.31$ & $22.40 \pm 21.78$ & $35.84 \pm 23.97$ * \\
\hline & $p^{\star \star}$ & $<0.0001$ & $<0.0001$ & $<0.0001$ & $<0.0001$ & $<0.0001$ \\
\hline
\end{tabular}

* $p<0.05$, refers to Wilcoxon test between full mouth-examination and each partial-mouth protocol models;

${ }^{\star *} \mathrm{p}$ refers to Kruskall-Wallis test.

Model I = All sites per tooth in a random half-mouth protocol (one maxillary and one mandibular);

Model II = Buccal sites in a full-mouth protocol;

Model III = Buccal sites in a random half-mouth protocol (one maxillary and one mandibular);

Model IV = All sites per tooth at Community Periodontal Index teeth;

Group $A=$ subjects with fewer than 4 sites with periodontal pocket depth $=4.0 \mathrm{~mm}$;

Group $B=$ subjects with at least 4 sites with periodontal pocket depth $\geq 4.0 \mathrm{~mm}$ and $\leq 6.0 \mathrm{~mm}$;

Group $C=$ subjects with at least 4 sites with periodontal pocket depth $>6.0 \mathrm{~mm}$.

mandibular quadrant would adequately reflect the full-mouth periodontal situation. Similar results were described by Brown et al. 25, who assessed the intra-oral distribution pattern of advanced periodontitis and found a high degree of bilateral symmetry of disease. Diagonally opposing quadrants of teeth and teeth on only one side of the mouth showed consistent periodontal pocket depth measurements ${ }^{15}$. Similar findings were reported by Owens et al. 18, who found similarities between mean percentage of periodontal pocket depth and clinical attachment loss $\geq$ $4.0 \mathrm{~mm}$ and $\geq 6.0 \mathrm{~mm}$ among full-mouth, upper and lower left/right quadrants, and random diagonal quadrants. However, conflicting results were found by Thompson and Williams 17, who examined 25 and 26-year-old subjects to test the validity of half-mouth quadrant protocols. All quadrant combinations ( 1 and 3, 2 and 4, and diagonal half-mouth approach) resulted in under- estimation of periodontal pocket depth $\geq 4.0 \mathrm{~mm}$ and clinical attachment loss $\geq 4.0 \mathrm{~mm} 17$.

There were statistically significant differences for periodontal pocket depth for shallow and moderate levels of periodontal pocket depth in Model II. Although Model II assessed the same number of periodontal sites as Model I, assessing only buccal sites (mesio-buccal, buccal, and disto-buccal), a full-mouth protocol led to the loss of precision compared to full-mouth examination for periodontal pocket depth measurements. Similarly, Model III had different mean periodontal pocket depth scores when compared to full-mouth examination. Underestimation of periodontal disease by Model III was consistent with Kingman et al. 24 , who found that periodontal pocket depth $=6.0 \mathrm{~mm}$ prevalence decreased from $14.3 \%$ (full-mouth examination) to $9 \%$ (MBD random half-mouth examination) 24 . The considerable reduction in the number of peri- 
odontal sites assessed in Models II and III confirms this result. The assessment of buccal sites in a full-mouth or half-mouth protocol did not adequately reproduce the full-mouth examination.

Underestimation of the prevalence of periodontal disease and incidence of periodontitis progression has been shown in previous studies testing protocols with considerable reduction in the number of periodontal sites assessed, including the "Ramfjord" teeth approach 13,14,18,20,24,26, $27,28,29,30$. On the other hand, there was overall high agreement between "Ramfjord" teeth and full-mouth periodontal pocket depth and clinical attachment loss assessment in a Tanzanian adult population 31 and in a Norwegian adolescent sample 32 . Statistical correlations between Ramfjord teeth and full-mouth examination were both positive and significant 19 .

In the present study, use of partial-mouth protocol Models II and III employing buccal sites and proximal sites assessed by buccal sides was justified by the easy clinical access to these areas and reduction in intra-examiner variability for periodontal parameters 14,15. Although buccal sites are more susceptible to loss of attachment due to non-bacterial processes, such as severe tooth brushing ${ }^{33}$, destructive periodontal disease is more frequent and severe in proximal sites compared to buccal and lingual periodontal sites 34 .

All periodontal clinical parameters measured in CPI teeth (Model IV) differed significantly from full-mouth examination, except for periodontal pocket depth $>6.0 \mathrm{~mm}$ in Group A, and for periodontal pocket depth and clinical attachment loss $4-6 \mathrm{~mm}$ in Group C. The differences were at least $25 \%$ between full-mouth examination and Model IV. There was an overestimation of periodontal disease for all periodontal parameters investigated (Table 3). As in Models II and III, one possible explanation for the lack of precision concerning CPI teeth is the considerable reduction in periodontal sites examined. Another explanation for this finding is that the teeth employed in CPI are incisors and molars. Assessment of the distribution of periodontal disease by tooth type showed that molars were most often affected by gingivitis and periodontitis. On the other hand, the maxillary central incisors were the least periodontally involved tooth type 34 . Since CPI employs eight molars and two incisors, the overestimation of periodontal disease observed in the present study is understandable. Therefore, when a limited number of sites at greater risk of loss of attachment level are chosen, overestimation tends to occur 7 .

Despite the criticisms of periodontal indexes 3 , the assessment of periodontal pocket depth and clinical attachment loss on several index teeth has been the most frequent procedure used to simplify full-mouth periodontal examination. Among all periodontal index teeth tested to substitute for full-mouth examination, the Ramfjord Index teeth 13,18,20,26,28,31,32,35, Periodontal Treatment Index teeth 26, Gingival Periodontal Index teeth 14 and the CPITN teeth 14,20,32,36 have been the most widely investigated.

The CPI classification system for assessing periodontal needs was developed by the World Health Organization and then widely recommended in the WHO Oral Health Basic Surveys Methods Manual 9. Therefore, most epidemiological surveys for periodontal disease conducted worldwide have used CPI. The overestimation of periodontal disease observed using CPI teeth in this study was similar to findings from other studies. In an overall comparison with fullmouth examination, the CPI teeth overestimated the mean periodontal pocket depth $>3.0 \mathrm{~mm}$ and periodontal pocket depth $>6.0 \mathrm{~mm} 36$, as well as the frequency of periodontal pocket depth 4$5 \mathrm{~mm} 20$, periodontal pocket depth $\geq 4 \mathrm{~mm} 32$, and periodontal pocket depth $\geq 6 \mathrm{~mm} 20,37$. However, as with Model I, when young adults and adolescents were assessed for periodontal disease, CPI teeth and the full-mouth approach were similar for periodontal pocket depth and clinical attachment loss measurements 14,32.

The consistency of the studies in obtaining distorted estimates of periodontitis prevalence using CPI in adult populations should stimulate a serious discussion concerning the real value of its use in epidemiological surveys 10,13,20,36.

Agerholm \& Ashley 14 found no differences between the partial-mouth protocol using CPITN teeth and full-mouth examination for moderate and deep periodontal pocket depth in young adult workers with low levels of periodontal disease. Similar results were found in the present study for frequency of periodontal pocket depth $>6.0 \mathrm{~mm}$ in Group A, consisting of subjects with fewer than 4 sites with periodontal pocket depth $=4.0 \mathrm{~mm}$ (Table 4 ). The very low frequency of severe periodontal disease in both samples, in contrast to the findings for the entire sample, highlights the importance of appropriate patient selection for testing partial-mouth protocol models.

In the present study the reliability of a random half-mouth protocol to reproduce full-mouth examination was robust for adult subjects with different levels of destructive periodontal disease. Further research is necessary to confirm the effectiveness of the random half-mouth protocol and thus suggest modifications to the WHO CPI method recommended to assess periodontal disease and treatment needs in epidemiological surveys. 


\section{Resumo}

O objetivo deste estudo foi comparar a confiabilidade para medidas periodontais de profundidade de bolsa à sondagem e nível clínico de inserção de quatro protocolos de registros parciais. Exames periodontais completos foram realizados em 156 indivíduos com idade $\geq 30$ anos. Quatro protocolos foram comparados ao exame periodontal completo: Modelo I: protocolo de dois quadrantes aleatórios, um superior e um inferior (seis sítios por dente), Modelo II: protocolo de quatro quadrantes (três sítios vestibulares por dente), Modelo III: protocolo de dois quadrantes aleatórios, um superior e um inferior (três sítios vestibulares por dente), Modelo IV: protocolo de seis sítios por dente nos dentes índices do Índice Periodontal Comunitário. Ao comparar com o exame periodontal completo, o Modelo I não apresentou diferenças para nenhum dos parâmetros periodontais, os Modelos II e III foram diferentes em algumas médias de profundidade de bolsa à sondagem. O Modelo IV superestimou todos os parâmetros clínicos associados à doença periodontal. O Modelo I pareceu ser apropriado para substituir o exame periodontal completo para caracterização da prevalência e severidade da periodontite crônica em populações adultas.

Doenças Periodontais; Saúde Bucal; Levantamentos Epidemiológicos; Protocolos

\section{Contributors}

M. V. Vettore designed the methodology and statistical analysis and wrote the article. G. A. Lamarca collaborated in the literature search and study design and participated in the final version of the article. A. T. T. Leão participated in the elaboration and implementation of the statistical analysis and provided orientation for the article. A. Sheiham provided orientation for the article and participated in the drafting and editing of the final version. M. C. Leal conducted the final revision.

\section{Acknowledgments}

The authors wish to thank the Fundação Carlos Chagas Filho de Amparo à Pesquisa do Estado do Rio de Janeiro (E-26/170.421/2003) and Pan-American Health Association/World Health Organization (Graduate Thesis in Public Health, First round, 2004) for financial support, Hu-Friedy do Brasil for periodontal probes, and the Conselho Nacional de Desenvolvimento Científico e Tecnológico (CNPq) for a PhD grant to the first author. The authors also thank Francisco I. Bastos from the Centro de Informação Científica e Tecnológica, Fundação Oswaldo Cruz (CICT/FIOCRUZ), for his support.

\section{References}

1. American Academy of Periodontology. Parameter on chronic periodontitis with slight to moderate loss of periodontal support. J Periodontol 2000; 71(5 Suppl):853-5.

2. Newman MG. Current concepts of the pathogenesis of periodontal disease. J Periodontol 1985; 56:734-9.

3. Kingman A, Albandar JM. Methodological aspects of epidemiological studies of periodontal diseases. Periodontol 2000 2002; 29:11-30.

4. Russell AL. A system of classification and scoring for prevalence surveys of periodontal disease. J Dent Res 1956; 35:350-9.

5. Greene JC, Vermillion JR. The simplified oral hygiene index. J Am Dent Assoc 1964; 68:7-13.

6. Ramfjord SP. The Periodontal Disease Index (PDI). J Periodontol 1967; 6 Suppl 38:602-10.

7. Carlos JP, Wolfe MD, Kingman A. The extent and severity index: a simple method for use in epidemiologic studies of periodontal disease. J Clin Periodontol 1986; 13:500-5.
8. Ainamo J, Barmes D, Beagrie G, Cutress T, Martin J, Sardo-Infirri J. Development of the World Health Organization (WHO) community periodontal index of treatment needs (CPITN). Int Dent J 1982; 32:281-91.

9. World Health Organization. Oral health surveys: basic methods. Geneva: World Health Organization; 1997.

10. Baelum V, Papapanou PN. CPITN and the epidemiology of periodontal disease. Community Dent Oral Epidemiol 1996; 24:367-8.

11. Cutress TW, Ainamo J, Sardo-Infirri J. The community periodontal index of treatment needs (CPITN) procedure for population groups and individuals. Int Dent J 1987; 37:222-33.

12. Alexander AG. Partial-mouth recordings of gingivitis, plaque and calculus in epidemiologic surveys. J Periodont Res 1970; 5:141.

13. Dowsett SA, Eckert GJ, Kowolik MJ. The applicability of half-mouth examination to periodontal disease assessment in untreated adult populations. J Periodontol 2002; 73:975-81. 
14. Agerholm DM, Ashley FP. Clinical assessment of periodontitis in young adults-evaluation of probing depth and partial recording methods. Community Dent Oral Epidemiol 1996; 24:56-61.

15. Hunt RJ. The efficiency of half-mouth examinations in estimating the prevalence of periodontal disease. J Dent Res 1987; 66:1044-8.

16. Papapanou PN, Wennstrom JL, Johnsson T. Extent and severity of periodontal destruction based on partial clinical assessments. Community Dent Oral Epidemiol 1993; 21:181-4.

17. Thomson WM, Williams SM. Partial or full-mouth approaches to assessing the prevalence of and risk factors for periodontal disease in young adults. J Periodontol 2002; 73:1010-4.

18. Owens JD, Dowsett SA, Eckert GJ, Zero DT, Kowolik MJ. Partial-mouth assessment of periodontal disease in an adult population of the United States. J Periodontol 2003; 74:1206-13.

19. Mills WH, Thompson GW, Beagrie GS. Partialmount recording of plaque and periodontal pockets. J Periodontal Res 1975; 10:36-43.

20. Ainamo J, Ainamo A. Partial indices as indicators of the severity and prevalence of periodontal disease. Int Dent J 1985; 35:322-6.

21. Vettore MV, Leao AT, Monteiro-da-Silva AM, Quintanilha RS, Lamarca, GA. The relationship of stress and anxiety with chronic periodontitis. J Clin Periodontol 2003; 30:394-402.

22. Russell AL. The periodontal index. J Periodontol 1967; 38 Suppl:585-91.

23. Kingman A, Albandar JM. Validity of partial recording of attachment loss in early-onset periodontitis. Periodontal Res 1997; 76:229.

24. Kingman A, Morrison E, Loe H, Smith J. Systematic errors in estimating prevalence and severity of periodontal disease. J Periodontol 1988; 59:707-13.

25. Brown LJ, Oliver RC, Löe H. Periodontal diseases in the U.S. in 1981: prevalence, severity, extent, and role in tooth mortality. J Periodontol 1989; 60: 363-70.

26. Eaton KA, Duffy S, Griffiths GS, Gilthorpe MS, Johnson NW. The influence of partial and fullmouth recordings on estimates of prevalence and extent of lifetime cumulative attachment loss: a study in a population of young male military recruits. J Periodontol 2001; 72:140-5.
27. Beck JD, Löe H. Epidemiological principles in studying periodontal diseases. Periodontol 2000 1993; 2:34-45.

28. Fleiss JL, Park MH, Chilton NW, Alman JE, Feldman RS, Chauncey HH. Representativeness of the "Ramfjord teeth" for epidemiologic studies of gingivitis and periodontitis. Community Dent Oral Epidemiol 1987; 15:221-4.

29. Downer MC. The relative efficiencies of some periodontal partial recording selections. J Periodontal Res 1972; 7:334-40.

30. Hunt RJ, Fann SJ. Effect of examining half the teeth in a partial periodontal recording of older adults. J Dent Res 1991; 70:1380-5.

31. Mumghamba EG, Pitiphat W, Matee MI, Simon E, Merchant AT. The usefulness of using Ramfjord teeth in predicting periodontal status of a Tanzanian adult population. J Clin Periodontol 2004; $31: 16-8$

32. Silness J, Røynstrand T. Partial mouth recording of plaque, gingivitis and probing depth in adolescents. J Clin Periodontol 1988; 15:189-92.

33. Sangnes G, Gjermo P. Prevalence of oral soft and hard tissue lesions related to mechanical tooth cleansing procedures. Community Dent Oral Epidemiol 1976; 4:77-83.

34. Schurch Jr. E, Minder CE, Lang NP, Geering AH. Periodontal conditions in a randomly selected population in Switzerland. Community Dent Oral Epidemiol 1988; 16:181-6.

35. Rams TE, Oler J, Listgarten MA, Slots J. Utility of Ramfjord index teeth to assess periodontal disease progression in longitudinal studies. J Clin Periodontol 1993; 20:147-50.

36. Aucott DM, Ashley FP. Assessment of the WHO partial approach in identification of individuals highly susceptible to periodontitis. Community Dent Oral Epidemiol 1986; 14:152-5.

37. Almas K, Bulman JS, Newman HN. Assessment of periodontal status with CPITN and conventional periodontal indices. J Clin Periodontol 1991; 18:654-9.

Submitted on 21/Dec/2004

Final version resubmitted on 19/Aug/2005

Approved on 14/Dec/2005 